\title{
Gondysia preceded Neadysgonia (Lepidoptera, Erebidae, Erebinae), a new generic synonymy from southeastern United States
}

\author{
J. Bolling Sullivan', Albert Legrain² \\ I 200 Craven St., Beaufort, North Carolina 28516 USA 2 Quai du Halage, 10, 4681-Hermalle (Liège), \\ Belgium \\ Corresponding author: J. Bolling Sullivan (sullivan14@earthlink.net)
}

Academic editor:D. Lafontaine | Received 28 June 2011 | Accepted 20 September 2011 | Published 24 November 2011

Citation: Sullivan JB, Legrain A (2011) Gondysia preceded Neadysgonia (Lepidoptera, Erebidae, Erebinae), a new generic synonymy from southeastern United States. In: Schmidt BC, Lafontaine JD (Eds) Contributions to the systematics of New World macro-moths III. ZooKeys 149: 103-106. doi: 10.3897/zookeys.149.1747

\begin{abstract}
The recently proposed genus Neadysgonia Sullivan, 2010, was preceded in the literature by Gondysia Berio, 1955, a monotypic genus based on specimens without locality labels but presumed to be from Madagascar. The genus Gondysia replaces Neadysgonia and the species G. pertorrida Berio, I955, becomes a junior synonym of $G$. consobrina (Guenée, 1852).
\end{abstract}

\section{Keywords}

taxonomy, Dysgonia, Gondysia, Neadysgonia, Madagascar, United States

\section{Introduction}

Recently, the genus Neadysgonia Sullivan was proposed for the North American species formerly placed in Dysgonia Hübner (Sullivan 2010). Berio (1955) described the monotypic genus Gondysia based on material presumed to be from Madagascar. Superficially, G. pertorrida Berio appears to be identical to specimens of Neadysgonia consobrina (Guenée). The purpose of this paper is to determine whether or not this possible synonymy is correct and, if so, to determine the taxonomic consequences of that finding. 


\section{Materials and methods}

During a visit to the British Museum in September of 2010 the type specimens of Gondysia pertorrida, their attached labels, and dissected genitalia, were photographed using a Cannon G10 camera and light box.

\section{Repository abbreviations}

BMNH Natural History Museum [statutorially: British Museum (Natural History)], London, UK

\section{Discussion}

During a visit to the $\mathrm{BMNH}$ we were able to examine the type specimens on which the name Gondysia pertorrida Berio is based. Adults were photographed as well as a slide preparation of the male genitalia of the type. The male and female of Gondysia pertorrida, with their labels, and the genitalia of the male holotype, are shown in Figure 1. British Museum records indicate that these specimens were obtained from M. P. Mabille who had a large amount of material from Madagascar and described many species from the island (bibliography in Poole 1989). The two type specimens in question were apparently obtained by Mabille via Oberthür. A. Guenée described most of the species currently in Neadysgonia but the types of all four of Guenée's species are missing. There is no indication of a collecting locality on the labels of the two types of G. pertorrida, but if these are the missing types for $N$. consobrina as discussed in Sullivan (2010), the location was probably near Savanna, Georgia, USA.

Figures 6, 12 in Berio (1955) are line drawings of the uncus and tegumen of $G$. pertorrida and are based on the genitalic preparation from the holotype in the BMNH. These closely resemble Figure 8a in Sullivan (2010) and examination of the slide in the BMNH (Agrotis 1126; E. Berio 1339) leaves no doubt that the type specimen of $G$. pertorrida Berio is conspecific with our concept of Neadysgonia consobrina (Guenée). All of the key characters are present.

Ophiusa consobrina Guenée was described from an unknown number of specimens from an unknown locality. No type material was found in the BMNH collections or those of the Paris Museum (Sullivan 2010). Neadysgonia consobrina is a very uncommon species throughout most of its range and it is not unlikely that $G$. pertorrida was described from the lost Guenée types.

Gondysia pertorrida, syn. n., is conspecific with Neadysgonia consobrina and thus is a junior synonym. However, the generic name Gondysia Berio is available and replaces Neadysgonia Sullivan, which is 55 years its' junior. Therefore, the North American species are as follows: 


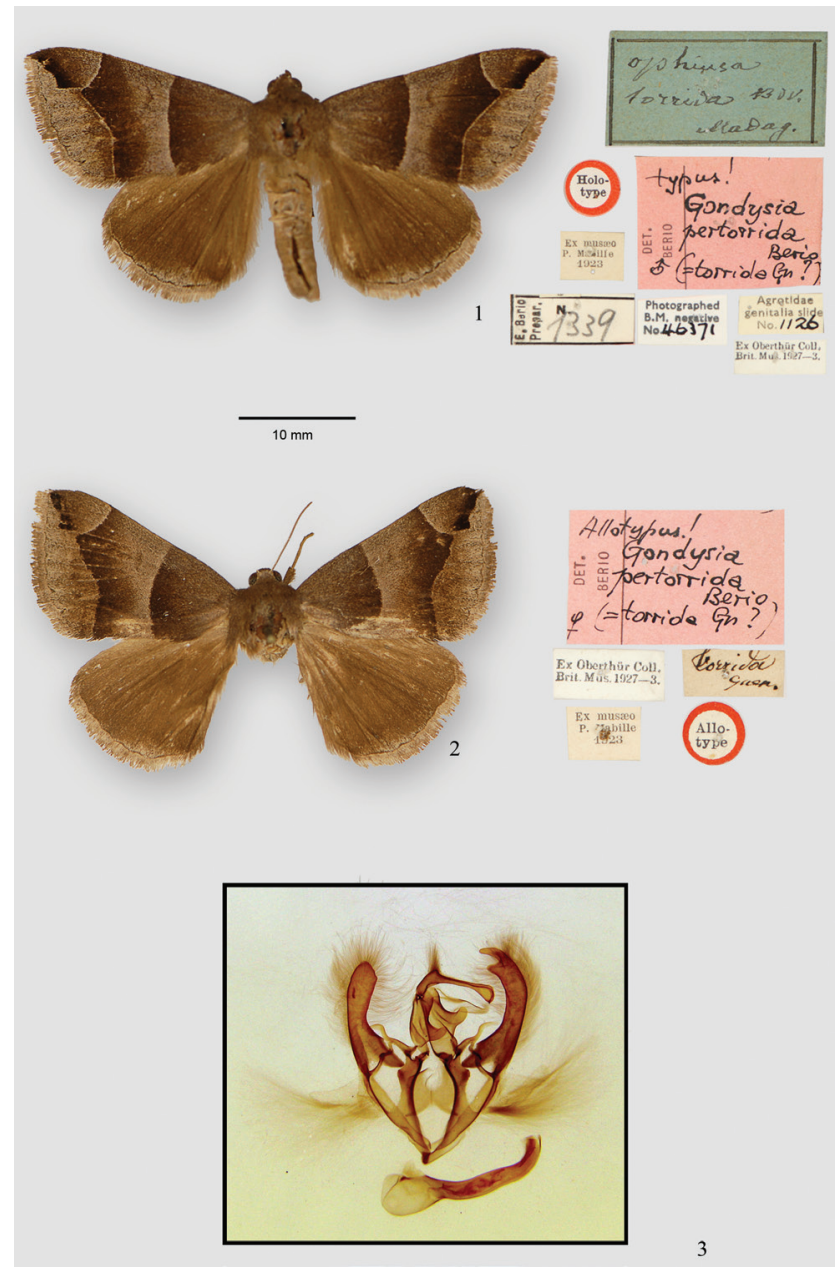

Figure I. Male and female types of Gondysia pertorrida Berio and their affixed labels. Genitalia (BMNH slide: Agrotis 1126; E. Berio 1339) of male holotype of G. pertorrida Berio.

Gondysia Berio, 1955

Parallelia, Auct. nec Hübner, 1818

Neadysgonia Sullivan, 2010, syn. n.

consobrina (Guenée, 1852), syn. n.

redditura (Walker, 1858)

pertorrida Berio, 1955, syn. n.

similis (Guenée, 1852), syn. n.

apicalis (Guenée, 1852)

concolor (Grote, 1893)

smithii (Guenée, 1852), syn. n.

telma (Sullivan, 2010), syn. n. 
Recent collecting and genitalic examination have extended the known range of $G$. smithii to northern Florida, G. telma to central Florida (Terhune Dickel pers. comm.), and of G. smithii to Virginia (Steve Roble, pers. comm.).

\section{Acknowledgements}

We would like to thank Jocelyn Gill and Don Lafontaine for help in preparing the figure and suggestions regarding the manuscript. Martin Honey graciously allowed us access to the collections under his care at the British Museum. Steve Roble and Terhune Dickel kindly provided additional data on the distribution of Gondysia based on their genitalic dissections.

\section{References}

Berio E (1955) Sulla distribuzione geographica della Noctua algira L. e sulle species affine (Lep.

Noctuidae). Bollettino della Societa Entomologica Italiana 85: 140-048.

Berio E (1965) Le catocaline africane a tibie spinose del Museo de Tervuren. Annali del Museo

Civico di Storia Naturale Giacomo Doria 75: 181-332.

Poole RW (1989) Lepidopterum Catalogus (New Series). Fascicle 118. Noctuidae (in 3 parts).

E.J. Brill/Flora and Fauna Publications, New York, 1314 pp.

Sullivan JB (2010) A new genus and species for Dysgonia (Lepidoptera, Erebidae, Erebinae)

from southeastern United States. ZooKeys 39: 85-97. doi: 10.3897/zookeys.39.434 